\title{
THE AGRARIAN QUESTION IN LIFE OF WESTERN KAZAKHSTAN SOCIETY IN THE 19 - EARLY 20 CENTURIES
}

\section{(C) 2016}

D.Y. Frizen, candidate of historical sciences, senior lecturer of the Chair of Social and Humanitarian Disciplines Baishev University Aqtobe, Aktobe (Republic of Kazakhstan)

\begin{abstract}
The agrarian question is a very urgent problem in Kazakhstan. The following paper shows the history of struggle for land in 19-20 centuries. At those times Kazakhs were nomads. Tsarism carried some reforms and made the lands in the Kazakh steppe the property of the state. In Western Kazakhstan agriculture, cattle breeding, trade developed. In the Kazakh steppe agrarian transformation started. Nomads started to build permanent dwellings. These buildings were near the Russian peasants. Construction of railways led to the fact that the Kazakhs and Russian peasants sold bread at the markets near stations. Stolypin agrarian reform accelerated the process of agrarian transformation. Eventually, Western Kazakhstan entered into Russian market.

Keywords: Western Kazakhstan; resettlement policy; agriculture; cattle breeding; transformation; the Younger zhuz; Inner Horde; Nomads; the social structure; the Kazakh society; peasant settlers; steppe; experimental field; XIX century; XX century.
\end{abstract}

УДК 94(47):327

\section{ДЕЯТЕЛЬНОСТЬ Н.В. ЧАРЫКОВА ПО РЕФОРМИРОВАНИЮ МИНИСТЕРСТВА ИНОСТРАННЫХ ДЕЛ РОССИИ} (C) 2016

О.А. Чернов, кандидат исторических наук, доцент кафедры отечественной истории и археологии Самарский государственный сочиально-педагогический университет, Самара (Россия)

\begin{abstract}
Аннотация. Проблема реформирования министерства иностранных дел Российской империи в начале XX века нашла освещение в исторической литературе. Однако роль Н.В. Чарыкова освещена весьма кратко. Поскольку он был председателем Совещания по реформированию министерства иностранных дел, представляется необходимым изучить его идеи и роль в данном преобразовательном направлении. Руководителем Совещания по реформированию центральных учреждений министерства иностранных дел он стал после того, как получил назначение на должность товарища министра иностранных дел. Это, в свою очередь, произошло после того, как министром иностранных дел стал А.П. Извольский - друг и однокурсник Н.В. Чарыкова по Александровскому Императорскому лицею. Н.В. Чарыков указывает, что А.П. Извольский пригласил его стать заместителем министра иностранных дел. Все юридические дела министерства иностранных дел были переданы А.П. Извольским в полное распоряжение Н.В. Чарыкову.

Н.В. Чарыков занимал должность товарища министра иностранных дел и возглавлял Совещание по реформе министерства иностранных дел, осуществляя вдумчивую и кропотливую работу. Он сумел наладить координацию действий всех ведомств, от которых зависело реформирование. Также он полагал необходимым изменение структуры министерства иностранных дел, увязывая её с необходимостью увеличения финансирования. Кроме того, выступал за расширение дипломатической переписки на русском языке. Важным моментом была мысль о необходимости демократизации дипломатического экзамена, с одной стороны, и одновременно повышении уровня образовательных требований к кандидатам - с другой.

Ключевые слова: Н.В. Чарыков; А.П. Извольский; М.А. Таубе; .Н. Губастов; .Н. Михайловский; И.А. Персиани; С.М. Горяинов; А.А. Нератов; В.О. фон Клемм; Г.А. Плансон; М.И. Муромцев; Ю.Я. Соловьев; К.К. Буксгевден; А.К. Бентковский; Александровский лицей; реформа; министерство иностранных дел; внешняя политика России; российская дипломатия.
\end{abstract}

Николай Валерьевич Чарыков - заметный государственный деятель Российской империи начала XX века [1;2] - принял непосредственное участие в преобразовании министерства иностранных дел России.

После того как МИД России возглавил А.П. Извольский, началось его реформирование. Под его руководством был разработан проект «коренной реформы МИД» [3, с. 85]. Е.Г. Кострикова указывает, что данная проблема назрела к началу XX века и многие дипломаты высказывали свои предложения в этом направлении. Решающим фактором стало назначение министром иностранных дел А.П. Извольского, который «без промедления приступил к подготовке общей реформы министерства» [4]. Как от- мечает В.Е. Авдеев, «одним из приоритетов деятельности А.П. Извольского на посту министра иностранных дел являлось решение проблемы реформы дипломатического ведомства, без которой модернизация всего механизма государственного руководства внешней политикой была лишена смысла» [5, с. 109; 6]. Российский внешнеполитический механизм получил подробное освещение в работах В.А. Емеца [7; 8], разбирались его аспекты в трудах А.В. Игнатьева $[9 ; 10]$.

Таким образом, проблема реформирования МИД России в начале XX века нашла освещение в исторической литературе. Однако роль Н.В. Чарыкова освещена кратко. Поскольку именно он был руководителем Совещания по реформированию централь- 
ных учреждений МИД, представляется необходимым изучить его деятельность в данном вопросе.

25 января 1908 г. товарищем министра иностранных дел был назначен Н.В. Чарыков - друг и однокурсник А.П. Извольского по Александровскому лицею [11, л. 7-8; 12, с. VII; 11]. Н.В. Чарыков вспоминал, что А.П. Извольский рассчитывал на его поддержку, планировал назначить его послом в Японии, но «в ноябре я [H.B. Чарыков - автор] снова получил от него [А.П. Извольского - автор] письмо, в котором он просил меня вместо этого стать заместителем министра иностранных дел» [13, р. 268]. Как свидетельствует М.А. Таубе, «юридические дела были переданы Извольским в верховное распоряжение товарищу министра» [14, с. 106].

У А.П. Извольского и Н.В. Чарыкова были общие подходы к организации дипломатической службы в России. Так, впоследствии, когда Николай II «обнаружил случайно, что Извольский и его заместитель, Н.В. Чарыков, ведут переписку не на французском языке, как делали их предшественники, а на русском языке, император был «радостно удивлен» [15, p. $452 ; 16$, p. 55].

11 июля 1908 г. А.П. Извольский подписал проект отношения к министру финансов и государственному контролеру, в котором указал, что «вполне выяснившаяся за последние годы неудовлетворительность организации министерства иностранных дел, не отвечающей требованиям настоящего времени, побудила меня, в минувшем 1907 г., образовать под председательством бывшего в то время товарища министра... Губастова особую комиссию, задача которой заключалась в пересмотре правил и условий службы по министерству иностранных дел и в разработке наиболее целесообразной организации центральных установлений министерства» [17, л. 2].

В связи с этим А.П. Извольский просил командировать чиновников, относящихся к ведомствам указанных руководителей, для участия в комиссии, которую он «в видах ускорения осуществления этого дела» был намерен образовать под председательством своего заместителя Н.В. Чарыкова [17, л. 2 об., 3].

21 августа 1908 г. министр финансов сообщал управляющему МИДом Н.В. Чарыкову, что с его стороны «не встречается препятствий, чтобы выработанный министерством иностранных дел проект новых штатов центральных установлений ... министерства был подвергнут рассмотрению в особой комиссии при названном министерстве».

28 августа 1908 г. управляющий МИД Н.В. Чарыков просил государственного секретаря командировать представителя «для участия в междуведомственную комиссию при министерстве иностранных дел под моим председательством» [17, л. 16]. В ответ на данный запрос командирован был А.А. Икскульфон-Гильденбант, а заместителем Г.В. Северин [17, л. 20]. Подобный же запрос был отправлен главноуправляющему Собственной Е.И.В. канцелярией [17, л. 17], в результате чего был направлен Г.В. Коробьин [17, л. 18].

Наконец, после подготовительной работы, 10 ноября 1908 г. состоялось первое заседание Совещания, образованного с целью развития и дополнения выработанного министерством иностранных дел проекта новой организации центральных установлений. Председателем совещания был Н.В. Чарыков, а его участниками К.К. Буксгевден, С.М. Горяинов, А.К. Бентковский, А.А. Нератов, Ю.Я. Соловьев, Г.А. Плансон, М.А. Таубе, М.И. Муромцев, В.О. фон Клемм, Н.В. Поггенполь, В.А. Березников, А.П. Вейнер и др. $[18$, л. 2].

Б.В. Лопухин, также участник совещания, оставил свидетельство о Н.В. Чарыкове при открытии Совещания: «В Чарыкове, большеголовом, маленьком человечке с некрасивым калмыцкого типа лицом и тонкими опущенными книзу усами, я без труда узнал раненого в турецкую войну гусара с рукою на перевязи, которому в 1878 г. за обедом у моей тетушки О.И. Батуриной тетушка и моя мать поочередно нарезали кушанья в тарелке. Он вежливо благодарил и что-то такое рассказывал, работая вооруженною вилкою здоровою рукою. Я любовался его гусарскими жгутами и восхищался его геройством. Тому прошло более 30 лет. Сейчас обе руки Чарыкова были здоровые. И на героя он не походил» [19, с. 181].

Заседание открылось в 9 часов вечера и окончилось в 12 1/2 ночи. Открывая заседание, Н.В. Чарыков отметил, что основные положения выработанного в начале этого года проекта новой организации центральных установлений министерства иностранных дел, составляющие минимум заявленных пожеланий, уже получили применение на практике, причем выяснилась необходимость несколько развить и дополнить данный проект. Н.В. Чарыков отметил, что «при изменившемся к лучшему состоянии нашего государственного казначейства казалось бы возможным провести реформу в более широкой мере и установить несколько более обширную программу для реорганизации ведомства» [18, л. 2 об.]. Как отмечает Е.Г. Кострикова, «он считал возможным увеличение штатов министерства» [20, с. 346]. Ввиду этого Н.В. Чарыков поручил К.К. Буксгевдену рассчитать возможное увеличение штатов министерства, о чем тот доложил на данном совещании.

Н.В. Чарыков полагал весьма полезным существование секретариата под руководством М.И. Муромцева. Причем, по его мнению, в состав данного органа должны были войти начальники департаментов и отделов МИД, а «секретариат этот должен заниматься подготовлением работ для Междуведомственной комиссии и разработать и представить законченный проект реорганизации и штатов министерства, руководствуясь постановлениями комиссии и настоящего совещания» [18, л. 3 об.].

Совещание поддержало инициативу Н.В. Чарыкова и приняло решение образовать секретариат. После этого Совещание рассмотрело ряд других инициатив. Так, Н.В. Чарыков предложил прочесть прилагаемую к данному проекту записку, составленную в департаменте личного состава и хозяйственных дел МИД, в которой были изложены предложенные начальниками отдельных частей изменения в проекте реорганизации центрального ведомства, возражения на некоторые предложения, а также перечень предложений, которые представляются приемлемыми. В связи с этим Н.В. Чарыков попросил участников совещания высказать свои замечания [18, л. 4 об.]. Сoвещание пришло к единогласному решению о со- 
хранении за Экспедицией наименования Первой $[18$, л. 5].

Н.В. Чарыков высказал мнение, что в случае увеличения окладов трех управляющих экспедициями с 4 тысяч до 5 тысяч, общее увеличение кредита выразилось бы всего суммою в 3000 рублей, а потому «было бы, может быть, справедливо признать это увеличение окладов возможным». В результате Совещание присоединилось к мнению Н.В. Чарыкова [18, л. 5 об.].

После этого Н.В. Чарыков поставил на обсуждение вопрос об устройстве одной большой библиотеки в одном учреждении, предложив оставить при архивах их специальные библиотеки и учредить должности библиотекаря VI класса, с окладом в 3000 рублей и его помощника VIII класса с окладом в 1600 рублей. В результате совещание поддержало идею Н.В. Чарыкова и постановило оставить библиотеку, как и хотел Н.В. Чарыков, при Втором департаменте $[18$, л. 6].

Затем Совещание под руководством Н.В. Чарыкова пришло к заключению о необходимости определить содержание директоров в 10500 рублей вместе с квартирными, а также о том, что общее увеличение штатов являлось бы вполне справедливым и желательным «для обеспечения как надлежащего личного состава, так и обмена такового между центральными и заграничными установлениями министерства» и что при выработке штатов Второго департамента должны быть приняты во внимание соображения, высказанные А.К. Бентковским [18, л. 6 об., 7].

Далее председатель перешел к рассмотрению «некоторых вопросов, касающихся устройства политических отделов» и высказал предположение, что ввиду того, что советники отделов, согласно мнению А.П. Извольского, «должны являться кандидатами на посты посланников, можно было бы приравнять их оклады, так же, как и оклады директоров, к окладам советников посольств, назначив им жалованье в 8500 рублей и с доплатой 2000 рублей квартирных» [18, л. 7]. При обсуждении следующего вопроса - об организации Третьей экспедиции - Н.В. Чарыков высказал мнение, что «3 штатных чина с причисленными едва ли справятся с предстоящей работой и что следовало бы увеличить состав штатных чинов Третьей экспедиции до 4 или 5, а причисленных к экспедиции назначат с таким расчетом, чтобы не менее половины их были уже опытными в деле шифрования и расшифрования» [18, л. 7 об.].

В результате Н.В. Чарыков поставил на обсуждение Совещания два варианта решения вопроса: «1) учреждать ли Третью экспедицию с добавлением двух штатных должностей и с назначением причисленных наполовину из опытных и наполовину из вновь поступивших на службу в министерство молодых людей» или «постановить, чтобы шифрование и расшифрование происходило в каждом из отделов с обязательным дежурством в Первом отделе и чтобы предлагаемая к ассигнованию на содержание Третьей экспедиции сумма в 18000 рублей была распределена между отделами». Н.В. Чарыков разъяснил, что причисленные будут равномерно командированы для обучения шифрованию [18, л. 8 об.].
После всестороннего обсуждения данного вопроса Совещание под руководством Н.В. Чарыкова «ввиду полного несогласия, выраженного на заседании комиссии, собиравшейся под руководством т.с. Губастова», постановила представить все соображения по данному вопросу на усмотрение министра А.П. Извольского [18, л. 8 об., 9].

Также председатель поставил вопрос об учреждении должности «начальника Архива всей политической части» $[18$, л. 9]. В итоге Совещание под руководством Н.В. Чарыкова выдвинуло ряд рекомендаций: увеличение содержания управляющего существующей Первой экспедицией до размера содержания управляющих другими экспедициями до 5000 рублей каждому; уравнивание окладов содержания по делопроизводительским должностям во всех центральных установлениях МИД; увеличение числа должностей: а) по Политической части - одною должностью секретаря VI класса, в качестве начальника Архива всей части и четырьмя должностями секретарей 2 - VII класса и 2 VIII класса, по одной в каждом отделе, в качестве помощников начальника Архива (в зависимости от разрешения министром вопроса об устройстве архивной части для политических отделов); б) по юрисконсультскому отделу одною должностью юрисконсульта-цивилиста (практика) с окладом в 2400 рублей; в) по Первой экспедиции - одною должностью делопроизводителя VI класса и одною должностью делопроизводителя VII класса. Увеличение сумм «на усиление средств» а) по Политической части - на 4800 рублей, для вознаграждения еще двух принятых, сверх предполагаемых пяти, в каждом отделе, считая по 600 рублей на каждого; б) по Первой экспедиции - отпуск 1800 рублей на вознаграждение двух сверхштатных чинов [18, л. 9 об., 10].

Кроме того, Н.В. Чарыков предложил сделать самостоятельными и уравнять в правах с другими отделами Юрисконсультскую часть и Отдел печати, подчеркнув, что «реформа центрального ведомства не будет удовлетворительной, если вопрос о сношениях с прессой не будет разрешен по примеру европейской практики» [20, с. 348].

18 ноября 1909 г. Совещание под руководством Н.В. Чарыкова собралось вновь. Состав совещания претерпел некоторые изменения. Помимо прежних участников совещания, к участию в нем был привлечен И.А. Персиани и другие участники $[18$, л. 50$]$.

Открывая заседание, Н.В. Чарыков выразил надежду, что «в настоящем собрании удастся придти к окончательному заключению по вопросу о реформе центральных установлений министерства иностранных дел» и поручил К.К. Буксгевдену сообщить участникам Совещания о достигнутых в этом вопросе результатах, а кроме того, «какое должно быть дано движение выработанным проектам». К.К. Буксгевден сообщил, что следует иметь в виду, что выработанные в комиссии по реформе, собиравшейся под председательством К.Н. Губастова, постановления относительно приема на службу по министерству иностранных дел, прохождения и т.д. не нашли себе выражения в предлагаемом проекте учреждений министерства. 
Н.В. Чарыков предложил признать необходимым включение в объяснительную записку указанные постановления, выработанные в губастовской комиссии [20, с. 348], и Совещание поддержало его инициативу $[18$, л. 50 об.].

Далее он поставил на обсуждение проект штатов центрального ведомства. Он предложил членам Совещания высказать свои замечания по поводу предлагаемой организации отдельных установлений центрального ведомства. В результате после краткого обмена мнениями Совещание под руководством Н.В. Чарыкова принимает в неизменном виде проекты штатов: непременных членов Совета, чиновников особых поручений при министре, канцелярии министра, литографии, Первого и Второго департаментов, Первого, Третьего и Четвертого отделов политической части, состоящих при политической части: драгоманов и регистратуры, Государственного и С. Петербургского главного архивов и Московского Главного архива МИД [18, л. 51].

При рассмотрении штатов Второго департамента А.К. Бентковский заявил, что они должны быть признаны достаточными для существующего ныне делопроизводства департамента, но могут оказаться недостаточными, если будет осуществлено предположение о необходимости обмена чинов между заграничными и центральными установлениями министерства.

Н.В. Чарыков предложил мнение А.К. Бентковского внести в протокол, но высказался против обсуждения данного вопроса в этом Совещании. Ибо созвано оно было для решения конкретного вопроса, а именно для выработки проекта реформы центральных установлений [18, л. 51 об.].

Далее Совещание под руководством Н.В. Чарыкова приняло решение внести изменения в проекты штатов других установлений. Так, в штатах Первого политического отдела признавалось необходимым, чтобы оба помощника как заведующий политическими делами, так и заведующий политическими делами Второго отдела находились на одинаковой ступени служебной иерархии, установить должность старшего секретаря, упразднив должность секретаря $\mathrm{V}$ класса. В штатах Юристконсультской части по тем же соображениям заменить должность секретаря V класса должность старшего секретаря с окладом соответствующим старшим секретарям других отделов; упразднить одну должность секретаря VII класса и обе должности помощников секретаря и отпустить на наем двух переписчиков по 720 рублей на каждого, а в сумме - 1440 рублей в год [18, л. 51 об., 52].

Совещание под руководством Н.В. Чарыкова отклонило ходатайство М.А. Таубе об обращении остатка от сокращения должностей по Юристконсультскому отделу на образование специальной библиотеки, так как К.К. Буксгевден разъяснил, что на приобретение книг и прочего в смете министерства имеется особый кредит, из которого и могут покрываться расходы на этот предмет. Также были сделаны изменения в штатах Первой и Второй экспедиций. В связи с уничтожением названия Второй экспедиции, Первую экспедицию было решено назвать Цифирной, а чиновников проектируемой Второй экспедиции считать состоящими при Политической части на суще- ствующих основаниях для чиновников, уже состоящих при канцелярии министерства. При обсуждении штатов, состоящих при политической части драгоманов и регистратуры, Совещание под руководством Н.В. Чарыкова признало необходимым, чтобы распределение драгоманов по политическим отделам, подчиненность их советникам отделов, привлечение их к занятиям в Отдел печати, а также надзор за деятельностью регистратуры были определены инструкциями, в соответствии с наказом министра А.П. Извольского [18, л. 52].

Дискуссионным стал вопрос о необходимости учреждения особой должности старшего архивариуса $\mathrm{V}$ класса при политической части. Против учреждения таковой от имени Секретариата Совещания высказался М.И. Муромцев. Он заявил, что в первых четырёх отделах Политической части предложено возложить ведение архивной части в каждом из них на делопроизводителя VI класса. При этом условии учреждение особой должности архивариуса как начальника над младшими чинами, ведающими архивной частью, поставило бы последних в двойную подчинённость: и от советников, и от старшего архивариуса, а с другой стороны, подчинённость самого этого архивариуса оставалась бы неопределённой [18, л. 52, 52 об.].

Н.В. Чарыков разрешил присутствующему на заседании И.А. Персиани изложить иную точку зрения, в пользу учреждения данной должности. По мнению И.А. Персиани, учреждение этой должности представлялось настоятельно необходимым для упорядочения архивного дела и ведения его в установленной системе [18, л. 52].

Н.В. Чарыков затруднился принять какое-либо единоличное решение и поставил данный вопрос на голосование. В результате 18 участников Совещания, в том числе и сам председатель, высказались против учреждения должности старшего архивариуса, а за учреждение высказалось лишь четверо [18, л. 52 об.].

Результаты голосования, ввиду разногласий, Н.В. Чарыков посчитал недостаточными для принятия определённого решения и признал необходимым представить данный вопрос на решение министра А.П. Извольского. Затем Совещание перешло к рассмотрению проекта учреждений МИД и заслушало участников. Председатель Совещания, Н.В. Чарыков предложил внести в журнал Совещания указание о том, что делопроизводство Юрисконсультского отдела будет охватывать, между прочим, вопросы, касающиеся Гаагских конференций [18, л. 53].

После обсуждения этого и других заявлений Сoвещание постановило: 1) При наименовании политических отделов добавить в скобках, после порядкового их обозначения, названия: к наименованию первого отдела название Западного, второго отдела Ближневосточного, третьего отдела - Среднеазиатского, четвёртого отдела - Печати, шестого отдела Юристконсульского; 2) Признать необходимым усилить требования знаний французского языка при приёме лиц на службу по министерству иностранных дел и выразить пожелание, чтобы, по меньшей мере, двое из чиновников особых поручений при министре несли обязанность редакторов французских бумаг политического и неполитического ха- 
рактера; 3) Включить в объяснительную записку по поводу ст. 817 п. 2 указания на дела, касающиеся в особенности Гаагских конференций; «Внести нижеследующие изменения: начало п. 4 ст. 800 редактировать следующим образом: Сношения с министерством императорского Двора о представленных к высочайшему Двору особ дипломатического корпуса, членов министерства иностранных дел и других лиц, положении траура и т.д. В ст. 812 исключить слова «и их коллеги». В ст. 815 прибавить слова «и Тихоокеанского побережья». В ст. 817 п. 1 и 2 изложить: П. 1 составляет заключение о нём международным вопросам политического свойства, которые нуждаясь в специальном обсуждении с юридической стороны, передаются на консультацию сего Отдела, по приказанию министра или его товарищей; П. 2. Заведует делопроизводством по особым вопросам юридического свойства, предаваемым ему по распоряжению министра или его товарищей; Ст. 820 изложить следующим образом: В состав Политической части при отделах Втором, Третьем и Четвёртом входят восемь драгоманов восточных языков; Ст. 821 В соответствии с изменениями в проекте штатов изложить их следующим образом: «При политической части состоят, в виде особого установления, Цифирная экспедиция, ведающая цифрами, с управляющим во главе, а также один старший и два младших чиновника»; В ст. 822 слово «подготовление» заменить словом «образование» согласно ст. 807 действующего Учреждения министерства [18, л. 53 об.].

Работа по реорганизации МИДа получила отражение в периодической печати. Санкт-Петербургская печать «Россия» от 27 февраля 1910 г. отмечала: «Существующее устройство центральных учреждений министерства иностранных дел, как отмечается в пояснительной записке к указанному проекту, в значительной мере не удовлетворяет предъявляемым к ведомству текущею действительностью новейшим требованиям, вследствие чего в устройство это надлежит ввести соответственные изменения. Соображая их, министр остановился на мысли об образовании в центральном ведомстве, из существующих его политических установлений - канцелярии и первого департамента, особой политической части» [21, л. 39].

Были и другие изменения. Как свидетельствует Г.Н. Михайловский, «со времени Извольского и Чарыкова ... вступительный дипломатический экзамен совершенно изменил свой характер ... и вопрос о приёме вновь поступающего решался ... коллегиально. Целый ряд дополнительных правил (возраст не старше 27 лет, обязательное высшее образование, преимущества для юристов и лицеистов...) сделали из этого экзамена солидный фильтр, чрезвычайно благоприятно отразившийся на уровне поступающих» [22, с. 35].

Н.В. Чарыков, занимая должность товарища министра иностранных дел и возглавляя Совещание по реформе МИД, осуществлял вдумчивую и кропотливую работу по её осуществлению. Он сумел наладить координацию действий всех отделов МИД и других ведомств, от которых зависело реформирование. Он полагал необходимым изменение структуры МИД, увязывая её с необходимостью увеличения финансирования, а также выступал за расширение дипломатической пе- реписки на русском языке и повышение профессионального уровня дипломатического экзамена.

\section{СПИСОК ЛИТЕРАТУРЫ:}

1. Чернов О.А. Дипломатическая деятельность и исторические взгляды Н.В. Чарыкова. Самара, 2010. $222 \mathrm{c}$.

2. Чернов О.А. Дипломатическая деятельность Н.В. Чарыкова в мемуарах современников // Самарский научный вестник. 2016. № 1(14). С. 102-106.

3. История внешней политики России. Конец XIX - начало XX в. М.: Международные отношения, $1993.668 \mathrm{c}$.

4. Кострикова Е.Г. Реформа Министерства иностранных дел России в начале XX века // Вестник Университета (Государственный Университет управления). М.: Государственный университет управления, 2011. С. 255-261.

5. Авдеев В.Е. А.П. Извольский - глава внешнеполитического ведомства России: 1906-1910 гг.: дис. ... канд. ист. наук. М., 2006. 239 с.

6. Авдеев В.Е. Александр Петрович Извольский // Вопросы истории. 2008. № 5. С. 64-79.

7. Емец В.А. Государственное руководство внешней политикой России в конце XIX - начале XX в. (сер. 90-х гг. ХІХ в. - февраль 1917 г.). Механизм принятия внешнеполитических решений. К постановке проблемы // К 75-летию начала Первой мировой войны: Материалы конференции. М., 1990. C. 28-30.

8. Емец В.А. Механизм принятия внешнеполитических решений в России до и в период Первой мировой войны // Первая мировая война. Дискуссионные проблемы истории. М.: Наука, 1994. С. 57-71.

9. Игнатьев А.В. Внешняя политика России. 1907 1914: Тенденции. Люди. События. М.: Наука, 2000. $233 \mathrm{c}$.

10. Игнатьев А.В. Внешняя политика России в конце XIX - начале XX в. Россия перед вызовами новой эпохи. М.: Геос, 2011. 220 с.

11. Российский государственный исторический архив (РГИА). Ф. 1405. ОП. 528. Д. 230.

12. Ежегодник Министерства иностранных дел за 1908 г. СПб., 1908. 300 c.

13. Tcharykow N.V. Glimpses of High Politics: Through War \& Peace, 1855-1929: The Autobiography of N.V. Tcharykow, Serf-Owner, Ambassador, Exile. London: G. Allen \& Unwin. 1931. 333 p.

14. Таубе М.А. «Зарницы»: Воспоминания о трагической судьбе предреволюционной России (19001917). М.: Памятники исторической мысли, Российская политическая энциклопедия (РОССПЭН), 2007. $272 \mathrm{c}$.

15. Tcharykow N.V. Reminiscences of Nicolas II. // Contemporary review. 1929. №3.

16. Tomaszewski, Fiona K. A great Russia: Russia and the Triple Entente, 1905-1914. Westport: ABCCLIO, 2002. 190 p.

17. Архив внешней политики Российской империи (АВПРИ). Ф. ДЛС и ХД. Оп. 731. Д. 95.

18. АВПРИ. Ф. ДЛС и ХД. Оп. 731. Д. 93.

19. Лопухин В.Б. Записки бывшего директора департамента Министерства иностранных дел. СПб.: Нестор-История, 2009. 540 с. 
20. Кострикова Е.Г. Внешняя политика в общественном мнении России накануне Первой мировой войны. 1908-1914 гг.: дис. ... д-ра ист. наук. М., $2011.473 \mathrm{c}$

21. АВПРИ. Ф. ДЛС и ХД. Оп. 731. Д. 27.

\section{N.V. CHARYKOV'S ACTIVITIES ON REFORMING THE MINISTRY OF FOREIGN AFFAIRS OF RUSSIA}

(C) 2016

O.A. Chernov, candidate of history sciences, Associate Professor of Domestic history and archeology

Abstract. The problem of reforming the Ministry of Foreign Affairs of the Russian Empire in the beginning of XX century was widely highlighted in historical literature. However, the role of N.V. Charykov is covered very briefly. Since he was the chairman of the council on the reform of the Ministry of Foreign Affairs, it seemed necessary to explore his ideas and role in this transformative direction. He became the head of the council on the reform of the Ministry of Foreign Affairs after he had an appointment to a deputy minister of Foreign Affairs. It happened after A.P. Izvolsky (N.V. Charykov's friend and classmate at Imperial Alexander Lyceum) had become a foreign minister. N.V. Charykov denotes that A.P. Izvolsky invited him to become the deputy minister of Foreign Affairs. All the legal affairs of the Ministry of Foreign Affairs were transferred under authority of N.V. Charykov by A.P. Izvolsky.

N.V. Charykov took up his post as the deputy minister of Foreign Affairs and was the head of the council on the reform of the Ministry of Foreign Affairs, implemented thoughtful and meticulous work. He could establish coordination among the actions of all the departments from which the reform was dependent on. Furthermore, he believed in the necessity of changing the structure of the Ministry of Foreign Affairs, linking it to the need to increase funding. Besides, he stood out for maintaining diplomatic correspondence in Russian instead of French. The important point was a democratization of the diplomatic exam on the one hand and an increase of the level of educational requirements for candidates on the other.

Keywords: N.V. Charykov; A.P. Izvolsky; M.A. Taube; K.N. Gubastov; G.N. Mihajlovsky; I.A. Persiani; S.M. Gorjainov; V.O. von Clemm; G.A. Planson; M.I. Muromtsev; Yu.Ya. Solov'ev; K.K. Buksgevden; A.K. Bentkovsky; Alexander imperial lyceum; reform; Ministry for Foreign Affairs; foreign policy of Russia; Russian diplomacy.

УДК 94(470.56)+37.014.22(091)

\section{ОБРАЗОВАТЕЛЬНАЯ И КУЛЬТУРНО-ПРОСВЕТИТЕЛЬНАЯ РАБОТА В КРАСНОЙ АРМИИ В 1920-1930-Е ГОДЫ: НА МАТЕРИАЛАХ ОРЕНБУРЖЬЯ}

(C) 2016
Л.В. Петрич, кандидат исторических наук, доцент кафедры истории России Оренбургский государственный педагогический университет, Оренбург (Россия)

Аннотащия. В статье освящается важный аспект в ликвидации неграмотности в годы Советской власти обучение красноармейцев и допризывников. От состояния грамотности данной категории населения в немалой степени зависела боеспособность Красной Армии. Проанализировав научную историческую литературу по данной теме, сделан вывод, что рассматриваемая тема изучена на сегодняшний день недостаточно. Отмечено, что во всей своей полноте проблема улучшения боевой подготовки Красной Армии встала в 1923 г., когда она перешла на мирное положение. В это же время был разработан декрет ВЦИК и СНК о привлечении к обязательным занятиям по ликвидации неграмотности всех допризывников во время прохождения ими допризывной военной подготовки. В работе выявлено, что в конце 1920 - начале 1930-х гг. работа по обучению красноармейцев и допризывников была продолжена во время культпоходов. Указано, что при организации обучения значительное внимание уделялось содержанию образовательного материала, связанного с политическим просвещением военнослужащих. Отмечены особенности, трудности и недостатки при организации работы с личным составом Красной Армии в Оренбуржье: низкая посещаемость ликпунктов, большой отсев из них. В статье сделан вывод, что система ликвидация неграмотности в тяжелые военные годы доказала свою крайнюю жизненную важность и необходимость в деле прямой защиты, укрепления и строительства государства. Это явилась важным фактором победы в Великой Отечественной войне.

Ключевые слова: ликвидация неграмотности; красноармейцы; допризывники; новобранцы; Красная Армия; неграмотные; малограмотные; воспитательная работа; политические занятия; культпоход; ликпункты; военнослужащие; образовательный уровень; политические отделы; комиссии по ликвидации неграмотности; культурно-просветительная работа; Оренбуржье.

В начале XXI века стало ясно, что последствия внутриполитического и экономического кризиса начала 1990-х гг. привели к усилению бездуховности, падению образовательного и культурного уровня будущих защитников Родины. К сложно- стям внутреннего порядка, характерным для движения России по пути радикальной модернизации, добавились трудности, обусловленные ростом международной напряженности, в частности, терроризмом. 